\title{
EMPODERAMENTO DA MULHER CUIDADORA DE CRIANÇAS COM NECESSIDADES ESPECIAIS DE SAÚDE ${ }^{1}$ EMPOWERMENT OF WOMEN CAREGIVER OF CHILDREN WITH SPECIAL HEALTH CARE NEEDS EMPODERAMIENTO DE LA MUJER CUIDADORA DE NIÑOS CON NECESIDADES ESPECIALES DE SALUD
}

\author{
Eliane Tatsch Neves ${ }^{2}$, Ivone Evangelista Cabral ${ }^{3}$
}

\begin{abstract}
${ }^{1}$ Recorte da tese de doutorado intitulada "O empoderamento de cuidadoras de crianças com necessidades especiais de saúde: interfaces com o cuidado de enfermagem", defendida junto ao Programa de Pós-graduação da Escola de Enfermagem Anna Nery (EEAN) em julho de 2007.

${ }^{2}$ Doutora em Enfermagem. Professor Adjunto do Departamento de Enfermagem da Universidade Federal de Santa Maria. Rio Grande do Sul, Brasil.

${ }^{3}$ Doutora em Enfermagem. Professor Associado do Departamento de Enfermagem Materno Infantil da EEAN. Universidade Federal do Rio de Janeiro. Orientadora da tese. Rio de Janeiro, Brasil.
\end{abstract}

PALAVRAS-CHAVE: Saúde da mulher. Cuidadores. em saúde.

KEYWORDS: Woman's health. Caregivers. Child health. Health education. Saúde da criança. Educação

RESUMO: A demanda de cuidados às crianças com necessidades especiais de saúde promove desgaste físico e mental da cuidadora. Para analisar as implicações dessas demandas sobre o empoderamento da cuidadora, desenvolveu-se uma pesquisa qualitativa. Onze cuidadoras acompanhantes, de um hospital do sul do Brasil, foram organizadas em três grupos, entre 2004-2005. Utilizou-se a análise de discurso no relatório de três dinâmicas do método criativo-sensível. O empoderamento individual das cuidadoras foi construído no enfrentamento das situações-limites dos cuidados e no encontro com os profissionais de saúde. O papel de boa mãe e de cuidadoras dedicadas, abnegadas levou-as a abdicar de sua condição feminina, gerando isolamento social, sofrimento e estresse. O empoderamento individual opressivo as distanciou do empoderamento coletivo libertador; a cuidadora foi valorizada em sua condição materna e não na feminina. As práticas de empoderamento individual, centradas na abnegação e dedicação, possibilitam a reflexão e ação no processo de empoderamento coletivo.

ABSTRACT: The demands of caring for children with special health care needs contribute to the physical and mental burden of female caregivers. Qualitative research was applied to analyze the implications of such demands on caregiver empowerment. Eleven caregiver guests at a university hospital in southern Brazil participated in three group dynamics of the creative-sensitive method, during 2004-2005. Discourse analysis was applied to the empirical data. The individual empowerment of caregivers was constructed by facing the limiting situations of care and the therapeutic encounter with clinicians. The role of 'good mother' gave mothers an individual empowerment, leading them to abdicate their feminine condition. However, they were under suffering, stress, oppression, and social isolation. Once caregivers were considered in their motherhood but not in their feminine condition, an individual empowerment distanced them from collective empowerment. The practices of individual empowerment, centered upon abnegation and dedication made reflection-action possible in order to promote the collective empowerment process.

PALABRAS CLAVE: Salud de la mujer. Cuidadores. Salud del niño. Educación en salud.

RESUMEN: La demanda de cuidados a los niños con necesidades especiales de salud promueve el desgaste físico y mental de la cuidadora. Para analizar las implicaciones de esas demandas sobre el empoderamiento de la cuidadora se desarrolló una investigación cualitativa. Once cuidadoras acompañantes, de un hospital del sur de Brasil, fueron organizadas en tres grupos, a partir de dinámicas del método creativo sensible, entre 2004 y 2005. En el informe de los grupos se utilizó el análisis del discurso. El empoderamiento individual de las cuidadoras fue construido en el enfrentamiento de las situaciones límites de los cuidados y en el encuentro con los profesionales de salud. El papel de buena madre y de cuidadoras dedicadas, generó aislamiento social, sufrimiento y estrés. El empoderamiento individual opresivo las distanció del empoderamiento colectivo libertador. Las prácticas de empoderamiento individual, centradas en la abnegación y dedicación, posibilitan la reflexión y la acción en el proceso de empoderamiento colectivo.
Eliane Tatsch Neves

Endereço: BR 158, 260, bl F1, ap. 201

97030-620 - Pinheiro Machado, Santa Maria, RS, Brasil

E-mail: elianev@terra.com.br
Artigo original: Pesquisa

Recebido em: 14 de janeiro de 2008 Aprovação final: 19 de agosto de 2008 


\section{INTRODUÇÃO}

A maior sobrevivência de crianças frente a agravos perinatais, doenças crônicas e traumas decorre dos benefícios da rápida evolução das indústrias de medicamentos e equipamentos. Essas crianças são denominadas na literatura internacional de Children With Special Health Care Needs (CSHCN), ${ }^{1}$ e no Brasil, como Crianças com Necessidades Especiais de Saúde (CRIANES). ${ }^{2}$ As necessidades especiais que essas crianças apresentam geram demandas de cuidados classificadas em quatro grupos: de desenvolvimento, tecnológico (dependente de tecnologia), medicamentosos e cuidado habituais modificados. ${ }^{3}$

Temos como exemplo de necessidades especiais e sua correlação com as demandas de cuidados, os que se seguem: as crianças com disfunção neuromuscular (de desenvolvimento); as crianças em diálise, as que fazem uso de gastrostomia (tecnológicos); as crianças com aids (medicamentosos) e as crianças que necessitam de cuidados especiais nas atividades de vida diária (habituais modificados). No domicílio, essas demandas de cuidados são intensas e se constituem em desafios para o cuidador familiar, em especial a mulher, realizá-las. Assim as CRIANES representam uma nova clientela pela complexidade dos cuidados, singularidade e fragilidade clínica. Para seus cuidadores, elas criam maiores demandas de cuidados em termos de constância, vigilância e intensidade.

No contexto da família, está socioculturalmente determinado, que a mulher é a provedora dos cuidados às crianças, idosos e doentes. Nesse contexto, a mulher assume o papel de cuidadora principal de CRIANES, dedicando-se integralmente ao cuidado. Os legados (da tradição, dedicação, abnegação, educação e socialização familiar e solidariedade feminina, aliados à obrigação moral) que são transmitidos culturalmente para as meninas da família, contribuíram para que elas internalizassem a função de cuidadora principal da família. ${ }^{4}$ Já o legado da dedicação, implica numa exclusividade da mulher para o desenvolvimento do papel de cuidadora de crianças, em particular daquelas com necessidades especiais de saúde. Esses legados reforçam que o papel da mulher para cuidar é uma construção social ideologicamente determinada, o que se constitui em uma obrigação moral. Nesse sentido, para as mulheres é delegada a responsabilidade do cuidado de toda a família, como uma obrigação moral socioculturalmente construída.
Entretanto, no caso específico das CRIANES, mulheres e homens da família são desprovidos de saberes e práticas relacionadas aos cuidados fundamentais de enfermagem para implementar os cuidados a essas crianças. Em sendo a tarefa de cuidar uma atividade essencialmente feminina, cabe a mulher não só a tarefa de cuidar, mas também, a de aprender a cuidar. Por sua vez, isso implica na necessidade de ter acesso às informações relacionadas aos saberes de enfermagem fundamental, incluindo aí os direitos de cidadania, o que envolve o processo de empoderamento. Estar empoderado, significa ter liberdade para tomar as suas próprias decisões, munidos de informações para isso. Nesse processo, destaca-se a reflexão sobre sua realidade, contexto político-social, representando o primeiro passo na transição para uma consciência crítica. ${ }^{5}$ O empoderamento pode, ainda, se apresentar em três níveis interativo, individual (psicológico), organizacional e/ou coletivo. ${ }^{6}$

Tendo por base essa construção sócio-cultural, os profissionais de saúde vêem na mulher um elo entre os serviços de saúde e a família. Alguns programas de saúde oficiais focalizam-na como principal responsável pelo cuidado da família, o que contribui apenas para o desenvolvimento de ações promotoras do empoderamento individual dessas cuidadoras. Em tese, as ações derivadas desses programas de atenção à saúde da mulher produzem padrões de maternidade que passam a fazer parte do senso comum ou são "naturalizados" pela sociedade. ${ }^{7}$

Não é incomum no dia-a-dia dos serviços de saúde, o profissional infantilizar o seu discurso ao interagir com as mulheres que são mães tratandoas como "mãezinhas". Muitas vezes, orientados por uma visão acrítica da realidade, os profissionais de saúde responsabilizam as mulheres pelo estado de saúde da criança, considerando que maternidade e cuidado infantil estejam unicamente relacionados ao processo de construção da identidade feminina. ${ }^{8}$ Assim, as questões sócio-culturais, incluindo gênero e identidade, transitam de mãos dadas com o conceito de empoderamento. ${ }^{4,9}$ Nesse sentido, gênero, identidade e cultura, em uma relação dialética, são indissociáveis e interferem no empoderamento da mulher cuidadora de CRIANES pertencentes à sociedade do sul do Brasil.

Em face à problemática da responsabilização da mulher pelo cuidado e sua necessidade de empoderamento nos três níveis interativos, para o cuidado de CRIANES, definimos como questão de pesquisa: como o empoderamento das cuida- 
doras, para atender as demandas de cuidados às CRIANES, interfere em seu bem-estar? Tem-se por objetivo analisar as implicações dessas demandas sobre o empoderamento dessas cuidadoras.

\section{METODOLOGIA}

Trata-se de uma pesquisa qualitativa, com uma abordagem crítico-humanista, pois se acredita na construção coletiva do conhecimento compartilhada com os participantes da pesquisa em sua expertise, bem como, na possibilidade de atuarem ativamente nesse processo de construção com sua subjetividade. Assim, a produção de dados foi desenvolvida de forma participativa, por meio do Método Criativo e Sensível (MCS) com 11 cuidadoras de 12 CRIANES procedentes de diversas unidades pediátricas de um hospital público..$^{10} \mathrm{O}$ cenário da pesquisa foi um hospital de grande porte, federal, destinado ao ensino, pesquisa e assistência à comunidade, que atende demandas de toda a região centro-oeste do estado do Rio Grande do Sul.

Os dados foram obtidos entre os anos de 2004 e 2005, nos serviços pediátricos da referida instituição; quando foram desenvolvidas, as três Dinâmicas de Criatividade e Sensibilidade (DCSs), do MCS (Corpo Saber, Mapa Falante e Linha da Vida) com as 11 cuidadoras sendo que, uma delas, é cuidadora de dois filhos CRIANES.,10-11

As DCSs combinam procedimentos de coleta de dados típicos da pesquisa qualitativa tradicional (observação, a entrevista e discussão de grupo) com as produções artísticas. Embora a concepção grupal imanente a DCS seja de pluralidade, a singularidade de cada participanteé preservada, pelo espírito democrático e participativo. As DCSs se constituem em um espaço onde são privilegiados momentos de integração entre o grupo, a ludicidade, o compartilhar de saberes e práticas entre sujeitos e pesquisador, construindo e validando juntos os conhecimentos novos. ${ }^{10}$

Nessa pesquisa, foi desenvolvida uma Questão Geradora (QG) de debate para cada dinâmica, em função de sua finalidade para atingir os objetivos propostos. Na primeira DCS (Corpo Saber), a QG foi: "como vocês cuidam de seus filhos ou filhas com demandas de cuidados especiais, em casa?" Na segunda (Mapa Falante), questionou-se: "tendo a casa, como ponto de partida, desenhe nesse mapa os lugares onde vocês levam os seus filhos ou suas filhas e quem são as pessoas que te ajudam a cuidar deles?" E na última (Linha da Vida): "como a sua experiência e trajetória de vida, tem contribuído para cuidar de seus filhos ou filhas?

O relatório das dinâmicas constituiu a fonte primária da pesquisa, cujo corpus do texto representou o material empírico que foi lido e interpretado segundo a Análise de Discurso francesa. Optou-se por esse método de análise de dados, pois o cotidiano do cuidado às CRIANES foi marcado por eventos constantes na história existencial das mulheres cuidadoras, como uma prática culturalmente naturalizada.

Então, o primeiro passo, após a delimitação do corpus, foi a realização de uma análise horizontal, em extensão, a "análise superficial". ${ }^{12}$

A primeira etapa do processo analítico consistiu na materialidade lingüística ao texto. Para tanto, foram utilizados recursos ortográficos, tais como - /: pausa reflexiva curta; //: pausa reflexiva longa; ...: pensamento incompleto; // /: pausa reflexiva muito longa; \#: interrupção da enunciação de uma pessoa, etc.

$\mathrm{Na}$ segunda etapa da análise chegou-se ao objeto discursivo, ${ }^{12}$ na qual foram empregadas as ferramentas analíticas que mostraram como funcionou o processo discursivo e os efeitos de sentidos que derivaram do discurso. Elegemos como ferramentas analíticas a metáfora, o interdiscurso, processos parafrásticos e polissemia.

A metáfora consiste na tomada de uma palavra por outra, estabelecendo o modo como ela significa. O interdiscurso é a relação do discurso com uma multiplicidade de discursos. Os processos parafrásticos, evidenciam que em todo dizer há sempre algo que se mantém; a polissemia rompe com a repetição, caracterizando os múltiplos sentidos produzidos pelo sujeito, o diferente do já dito.

$\mathrm{Na}$ terceira etapa chegou-se a formação discursiva dos seus enunciadores que denotou a formação ideológica dos sujeitos. ${ }^{12}$

O estudo foi aprovado pelo Comitê de Ética em Pesquisa, da Universidade Federal de Santa Maria, Protocolo No 093/2004 e todos os participantes assinaram o Termo de Consentimento Livre e Esclarecido, após explicação dos propósitos da pesquisa. Foram atribuídos nomes fictícios às mulheres participantes do estudo para garantir o anonimato das mesmas.

\section{RESULTADOS}

No decorrer das DCSs, as cuidadoras relataram os modos como a condição da criança influen- 
ciou suas vidas e os enfrentamentos necessários para atender as necessidades da criança. Relataram as trajetórias por elas percorridas desde a definição e o conhecimento do diagnóstico médico da condição da criança durante a gestação, no momento do parto e/ou como conseqüência de uma doença aguda acrescida de uma internação prolongada.

$\mathrm{O}$ atendimento das demandas de cuidados de sobrevivência das crianças ocasiona estresse e sofrimento, exigindo superação dos desafios apresentados no cotidiano conforme expresso por Raquel: [...] então eu já superei muitas barras mesmo, bastante difíceis, bastante pesadas, tudo só aqui [apontando para o próprio peito].

Essas trajetórias de cuidado expressaram sofrimento, luta, o modo como esse acontecimento interferiu e interfere na sua dinâmica familiar e no seu bem-estar. Dessa forma, destaca-se algumas trajetórias de cuidado relatadas nas DCSs para discutir a dimensão afetiva das cuidadoras e as interfaces do processo de cuidar de CRIANES com o empoderamento e o bem-estar dessas.

Da DCS - Corpo Saber, tem-se as trajetórias de Raquel, Lúcia e Ana: [...] eu passava a semana toda, de segunda à sexta, quando o J. nasceu, eu passava direto na fisioterapia com ele, pra recuperar os movimentos firmeza, tudo. [...] E levava as minhas crianças e deixava com minha sogra, com minhas cunhadas com a avó pra ajudarem a cuidar. [...] Tinha dias que parecia que eu não ia agüentar [...] E o meu marido trabalha fora, na cidade de B. [município distante cerca de $250 \mathrm{Km}$ ] e eu enfrento tudo sozinha, somente, praticamente sozinha, só com os médicos e a enfermagem (Raquel).

A agenda de vida de Raquel foi alterada em função dos constantes deslocamentos e do tempo dedicado à permanência do filho nas sessões de fisioterapia: [...] eu passava a semana toda [...] direto na fisioterapia (Raquel). A (re)organização da rede familial feminina de cuidados, foi uma iniciativa para dar conta das demandas de seus dois filhos com necessidades especiais de saúde e seus outros seis filhos. Raquel ressalta que a convivência com a condição dos dois filhos CRIANES gerou desgaste físico e emocional. Houve momentos em que parecia que não agüentaria (Raquel). A intensa demanda de cuidados levou a mulher cuidadora à situação-limite do esgotamento físico e mental.

Entretanto, mesmo diante desse desgaste, as mulheres cuidadoras de CRIANES, influenciadas pelas matrizes socioculturais da socialização no contexto da família e da sociedade, assumiram o papel social de cuidadoras e desenvolveram um cuidado solitário e solidário. Certamente, essa relação de subordinação ao mesmo tempo em que as isolaram socialmente, as empoderaram, no nível individual, para o desenvolvimento do cuidado. Enfrentar tudo sozinha foi motivo de orgulho de si mesma por ter superado, sozinha, todas as dificuldades "barras" que se apresentaram em sua trajetória de cuidadora.

Lúcia, que tem uma trajetória de 10 anos como cuidadora de CRIANES, enuncia: [...] Então, quando ela nasceu pra mim foi assim sabe //: um susto! A minha segunda decepção é que ela [a médica] chegou pra mim e falou assim: 'olha mãe a sua filha tem três meses de vida.' [...] De noite eu dormia e pensava será que está morrendo? E ficava assim como se tivesse entrando em depressão. E aquilo foi angustiante pra mim. Ta peguei ela e ficava assim olhando, tinha noite que eu dormia tinha noite que eu não dormia observando ela. Então, foi difícil no começo, principalmente, porque o pai dela não me ajudava em nada. [...] Ela não dorme separada, dorme junto com a gente [hoje, com o novo companheiro]. Ela [a filha de 8 anos] necessitou sim de uma psicóloga porque ela estava entrando em depressão. Agora eu posso dizer que estou superando e estou nessa aí a té o final (ri). [...] acima de tudo é Deus ///: que dá força a gente, [...]. É um dom que Deus dá pra gente que eu não sei de onde vem! Essa força pra segurar, //: cuidar das crianças, ///: eu não sei (Lúcia).

Lúcia, desde que recebeu o diagnóstico de D., vive mediada por sustos e decepções diante da possibilidade da morte da criança ser anunciada várias vezes, no percurso de sua condição clínica. Aqui, a fragilidade clínica dessas crianças é apontada como fonte geradora de estresse e sofrimento. A vigilância constante do estado de saúde da criança e o seu engajamento solitário nas ações de cuidar afetaram o seu bem-estar, causando-lhe depressão, angústia e insônia.

Associado a isso, o marido de Lúcia (pai de D.) deixou a família logo após o seu nascimento. Com isso, ela teve de enfrentar tudo sozinha. Mais tarde, tentou (re)construir sua vida com um segundo relacionamento do qual tem uma segunda filha (M.), que é com quem ela compõe a sua estrita rede familial de cuidados. Também, M. teve seu bem-estar afetado pela condição da irmã, que necessitou de tratamento psicológico. Lúcia atribui a força para cuidar da filha a algo superior (Deus).

Ana teve conhecimento do diagnóstico médico de G. durante a gestação: eu fui descobrir que o G. ia ter hidrocefalia e mielomeningocele com oito meses de gestação. Aí eu me desesperei, né? Porque eu não sabia direito o que era, o ginecologista falava, falava, falava, 
mas aquela língua de doutor que tu não entende, né [...] Aí eu tinha os outros seis [filhos] que já estavam convivendo comigo dentro de casa e eles estavam vendo que eu estava meio em pânico. [...] Aí quando eu fui visitar o G. na UTI, [...], eu encontrei uma enfermeira maravilhosa, [...] em primeiro lugar agradeço a ela sabe? [...] Chorei um monte de ver daquele estado com a coluna enfaixada, aquilo tudo. [...]. Aí ela (a enfermeira) chegou pra mim e foi me explicar. Eu achei que ela era até doutora (médica) sabe? [...] saí de lá assim ó //: \#: [...] aliviada!!!! Foi quando eu comecei a entender [...]. Enfrentei todos os problemas, sozinha. Ai foi bem difícil sabe? Me senti sozinha. [...] daí a minha vizinha ficou com as minhas crianças (Ana).

Ana se desesperou ao saber do diagnóstico de G. porque não sabia nada sobre a doença. Ela aponta o não entendimento da linguagem médica como um dos fatores que aumentaram, ainda mais, o seu desespero, chegando a declarar que estava meio em pânico (Ana). Ana relatou que os seus outros filhos acompanharam o seu sofrimento. Ela só se sentiu aliviada quando compreendeu o que estava acontecendo com G. por uma enfermeira da unidade de terapia intensiva neonatal. O pai de G. não vive com Ana; portanto, ela enfrentou tudo sozinha, encontrando em uma vizinha o suporte que a ajudou a cuidar dos outros filhos.

A similaridade entre as três trajetórias descritas está na solitude e no isolamento das cuidadoras ao enfrentar a realidade da condição das CRIANES sozinha, ou, por vezes, somente entre as mulheres da própria família, reforçando o caráter paradoxal desse cuidado, solitário e solidário.

Em todos os casos, ou o pai da criança abandonou a família, ou trabalha em uma cidade distante (Raquel) e, portanto, não participa do processo de cuidar. A ausência do papel masculino, inclusive como cuidador secundário, reforça o caráter feminino desse cuidado. Outro fato comum a todas elas é a (re)organização da dinâmica familiar ao compartilhar o mesmo quarto com a criança para monitorar o seu estado de saúde.

Nas trajetórias das cuidadoras, destaca-se a recorrência do profissional médico como o responsável pelo fornecimento de informações sobre a condição da criança, o tratamento e a forma de implementar os cuidados. Poucas vezes, a enfermagem é mencionada no discurso dessas cuidadoras. Quando a atuação da enfermeira é destacada, no caso de Ana, é confundida com o profissional médico.

Da DCS - Linha da Vida, selecionou-se os discursos de Luna e Tereza, conforme seguem: [...]
Porque o M. [atual companheiro] não vive, assim o que eu vivo, né? Pelo que eu tenho, assim, eu vivo em outro mundo, mas em relação a ele mesmo, né? Então, um pouco assim na verdade tu acaba tendo duas vidas, né? Eu acabo tendo duas vidas: uma aqui dentro [do hospital] e uma lá fora. Não que uma não interfira na outra, né? Com certeza a daqui mais que a de lá [...]. Com certeza, quando eu saio daqui [do hospital] eu não me desligo daqui, né? [...] porque eu venho [para o hospital] e passo toda tarde. [...] como é que tu vai parar pra pensar, tu vai sofrer todos os dias aquilo? Tu morre /: de tristeza, né?!!! [...] Mas assim, no começo, eu não ficava um dia [enfatizado] sem vir no hospital, mas capaz!! [...] Só que hoje eu consigo fazer isso, assim, de sair ..., duas vezes no mês eu não venho no hospital, ou de vez em quando, assim, eu vou viajar, fico dois, três dias fora, assim (Luna).

Luna, 24 anos, cuidadora de uma CRIANES que se encontrava internado na terapia intensiva pediátrica há seis anos, ressalta que ela vive em dois mundos e possui duas vidas, em comparação com seu companheiro. O mundo do hospital se referindo à vida "daqui", e o mundo fora do hospital, se referindo à vida "lá fora". Ela assume para si, toda a responsabilidade sobre o cuidado pelo fato de o companheiro não ser o pai da criança. Ao comportar-se dessa forma, acredita que está protegendo o seu relacionamento com ele. Luna sempre enfrentou tudo sozinha, pois sua família reside em outro estado, assim como o pai de L.H., que só telefona eventualmente para saber do menino.

A cuidadora ressalta que, após seis anos de hospitalização do filho, está começando a pensar mais em si mesma. Apesar do sentimento de culpa que isso ocasiona, pelo menos duas vezes no mês ela se afasta do hospital. O sentimento de culpa está presente quando ela diz não pensar nisso todos os dias para não sofrer tanto e, também, quando ela refere: [...] às vezes eu sou um pouco egoísta comigo mesma. Assim /: vou pensar um pouco mais em mim. (Luna).

Assim como Luna, Tereza também apresenta um discurso que denota uma transitividade de consciência em busca da libertação, como a seguir: eu acho que a gente tem que cuidar do filho, [...] a gente não pode se descuidar da gente, /: dos outros filhos, mas cabe, principalmente, a mãe/: saber separar e/: se dedicar da maneira possível a cada um, de maneira especial. Mas nunca esquecer da gente porque na hora que esquecer da gente vai perder todo mundo! (Tereza).

O compartilhar de vivências e experiências dessas mulheres durante as DCSs, foi denotado 
pelos vários diálogos nesse sentido, bem como pelo próprio relato delas ao final das dinâmicas. Esse compartilhar não só enriqueceu a bagagem de informações sobre a doença e o tratamento dos filhos e filhas de cada uma mas, também, se constituiu em uma fonte de empoderamento coletivo.

Desse modo, pode-se afirmar que a sobrevivência dessas CRIANES é resultado da dedicação das mulheres cuidadoras ao cuidado. Elas buscam por seus próprios meios, de forma individual e solitária, condições para o desenvolvimento desse cuidado. Por ser solitária, essa busca se constitui em fonte de sofrimento e estresse, pois lhes faltam subsídios para uma construção coletiva do cuidado.

\section{DISCUSSÃO}

As mulheres cuidadoras de CRIANES vivem em uma situação de opressão que causa sofrimento e estresse, comprometendo o seu bem-estar. Para ser uma boa mãe, atendendo o legado da obrigação moral, a cuidadora necessariamente tem de ser atenciosa, dedicada, zelosa e abnegada. ${ }^{4}$ Nesse sentido, elas se isolam, reduzindo sua rede de suporte social à rede familial constituída, basicamente, por mulheres. Tal dedicação e isolamento, por vezes, ocasionam o rompimento afetivo (separações conjugais) e social, e/ou a necessidade de (re) organização da dinâmica familiar., ${ }^{43-15}$

Todas as cuidadoras iniciaram a narrativa de suas vivências partindo do momento em que receberam a notícia do diagnóstico médico da criança, momento este em que começaram a se mobilizar para o enfrentamento da situação. $\mathrm{O}$ senso de empoderamento individual é desencadeado no momento em que mulher recebe o diagnóstico médico da criança constituindo-se, no momento zero do processo. ${ }^{16}$

Relacionando os achados de estudo do desencadeamento do estresse e coping, em mulheres com diagnóstico médico de câncer de mama com a situação vivenciada por mulheres cuidadoras de CRIANES, identifica-se o recebimento da notícia sobre a condição da criança como um fator externo desencadeador do processo de estresse. É nesse movimento que podem entrar em cena os fatores de avaliação primários e secundários e os moderadores internos e externos da situação. ${ }^{17-18}$ Os moderadores externos referem-se à estrutura, tais como: rede de suporte social, familiar, serviços, etc.

Nesse sentido, algumas cuidadoras buscam na equipe de saúde informações que as ajudem no enfrentamento da situação. Outras cuidadoras buscam esse suporte na rede familiar mais próxima. Inicialmente, todas desejam compartilhar a responsabilidade do cuidar com outras pessoas. Dessa forma as redes de cuidados familial e institucional às CRIANES começam a ser constituídas, tendo por base, as matrizes socioculturais e seus legados.

Essas matrizes socioculturais mediam os esforços que perpassam pela necessidade de apropriação de saberes e práticas do campo profissional e pela reprodução de práticas culturais de cuidados em saúde. Com isso, pode-se afirmar que tais esforços para cumprir o papel de boa mãe se constituem em uma fonte de estresse crônico para as mulheres cuidadoras.

A exposição permanente da pessoa a um estresse crônico pode repercutir na sua saúde física e mental, portanto, em seu bem-estar. Isso ocorre com maior freqüência entre as mulheres que assumem a responsabilidade de cuidar de crianças associadas a outras atividades cotidianas. Assim, essas mulheres cuidadoras estão expostas a um alto nível de estresse crônico, visto que o seu cotidiano se restringe quase que unicamente à atividade de cuidar de crianças com necessidades especiais de saúde.

Assim, a necessidade de cuidados de sobrevivência das CRIANES implica uma dedicação incondicional da mulher como cuidadora principal da criança, expressa pela vigilância constante do sono, tornando-a vulnerável em sua dimensão afetiva. Em muitas culturas, problemas na família e na comunidade são associados ao desenvolvimento de doenças físicas, constituindo-se em um fenômeno denominado sociossomatização. ${ }^{19}$

Nesse sentido, a forma como elas enfrentam a situação está diretamente relacionada com o seu contexto social e cultural, podendo estar relacionada com uma das cinco abordagens de coping, quais sejam de fuga, de ativo, de confronto, de ansioso e de fatalístico. ${ }^{17}$ Nesse estudo, as cuidadoras demonstraram que passam por todos eles, buscando diferentes modos de lidar com a situação, tentando torná-la menos estressante e, portanto, menos prejudicial ao seu próprio bem-estar.

Dentre essas formas, identificou-se, como um moderador interno utilizado pelas cuidadoras de CRIANES, o mito da boa mãe como um desejo imperioso - todas almejam ser boas mães. ${ }^{4}$ Entretanto, esse mito é uma construção social e representa o social infiltrado no individual. Nessa busca de ser uma boa mãe, elas utilizam os moderadores externos da cultura e de gênero em que quanto mais "boa mãe" ela for, mais ela será reconhecida 
pela sociedade. A cuidadora é valorizada em sua condição materna e não na feminina. De certa forma, isso contribui para o seu bem-estar, pois aumenta a auto-estima e lhe proporciona uma pseudo-segurança para cuidar do filho, reforçando o empoderamento individual.

Dessa maneira, pode-se afirmar que, dependendo da sua estrutura social (rede social, familial e cultural), a mulher cuidadora terá diferentes respostas ao estresse estabelecido a partir do conhecimento do diagnóstico médico do seu filho. $\mathrm{O}$ sofrimento, por sua vez, é uma reação psicossocial ao estresse que pode se manifestar por emoções negativas como depressão, ansiedade, medo e raiva. ${ }^{17-18}$ Tais sentimentos estiveram presentes nos enunciados das cuidadoras, especialmente no início do processo vivencial com a necessidade especial de saúde da criança, traduzidos pela negação e a raiva.

$\mathrm{O}$ "poder" conferido à mulher pelas matrizes sócio-culturais do cuidado lhe dá suporte psicológico para lidar com a situação, possibilitando seu processo de empoderamento individual. Assim, o empoderamento individual tendo por base essas matrizes, representa uma forma de coping adotado pela mulher cuidadora de CRIANES para enfrentar a situação de estresse que lhe é apresentada.

Com isso, ela se sente habilitada para enfrentar a situação e para compartilhar sua experiência com outras mulheres cuidadoras de CRIANES. A partir disso, ela pode dispor da rede de suporte social que poderá se constituir em uma fonte de empoderamento coletivo. ${ }^{16}$ Estudos apontam que a aquisição de conhecimentos acerca da doença, do tratamento e dos recursos disponíveis pode diminuir significativamente os níveis de ansiedade e estresse da família da criança. ${ }^{13,16,20}$ Nesse sentido, percebeu-se que a troca de experiências entre as cuidadoras de CRIANES durante a produção dos dados dessa pesquisa representou uma fonte de empoderamento coletivo.

As mulheres cuidadoras falaram sobre a necessidade de retomar uma vida "normal"; porém, esse normal foi ressignificado como resignação. Apontaram o tempo como fundamental para que elas aprendam a lidar com as muitas variáveis que envolvem o cuidado a CRIANES. Dessa forma, existe associação entre o tempo e a troca de experiências (convivência) com outras mães de CRIANES como fontes de empoderamento., ${ }^{415-16,20}$

Nesse sentido, a mulher cuidadora de CRIANES necessita de um "tempo", o qual não é cronológico, mas sim, singular a cada uma delas, dependendo de seu contexto, de sua história de vida, da menor ou maior influência das matrizes sócio-culturais do cuidado. Assim, a rede de suporte social a que ela tem acesso, o compartilhar de informações, experiências e vivências nas interações sociais e com profissionais de saúde em uma relação dialógica podem contribuir para o desenvolvimento do empoderamento coletivo.

\section{CONSIDERAÇÕES FINAIS}

A dedicação exclusiva ao atendimento das demandas de cuidados de sobrevivência da criança refletiu-se no bem-estar das cuidadoras, ocasionando um desgaste físico, emocional e afetivo. Para lidar com a situação de estresse e sofrimento desencadeada pelo recebimento do diagnóstico da criança, elas recorrem aos moderadores externos (rede familiar e institucional) e aos moderadores internos (matrizes socioculturais) do estresse para aliviar o seu sofrimento.

Assim, as mulheres cuidadoras vivem em um círculo de opressão composto pela matriz sociocultural do cuidado e seus legados que a fazem assumir o papel de cuidadora abnegada, dedicada e boa mãe em prol do cuidado do filho. Isso as conduz ao isolamento social, sofrimento e estresse, afetando negativamente o seu bemestar. Dessa forma, para suportar e lidar com as situações-limites dos cuidados elas se empoderam individualmente, tendo por base as matrizes socioculturais do cuidado e seus legados e no encontro com os profissionais de saúde.

Tal situação determina a impossibilidade de transição para uma consciência crítica que poderia representar a libertação, rompendo com a cultura do silêncio, com o círculo de opressão e levando-as ao empoderamento coletivo e à transformação social.

A despeito dessa situação opressiva, algumas delas ensaiam os primeiros passos na luta pela transformação da realidade. Essa luta é caracterizada por dois movimentos internos à própria família, de mulher para mulher, perpetuando, assim, as relações de opressão. A tentativa de (re)organização familiar (constituição de novos relacionamentos) e a busca pela normalização da vida para conviver com a condição da criança agregam apenas atitudes que preservam a si mesmas pelos caminhos da opressão, do sofrimento, da culpa e da dor.

Esses movimentos modificam-se associados ao tempo de convivência com a condição da criança, 
ou seja, quanto maior for o tempo de convivência maior é grau de sensibilização para a transformação da realidade vivenciada. Podemos concluir que o tempo é um fator chave que, ao mesmo tempo, contribui para o empoderamento individual e abre fendas para o empoderamento coletivo.

Tendo em vista a teoria freiriana, a mulher cuidadora, por meio do conhecimento/educação como instrumento libertador, é quem pode fazer a tomada de consciência buscando o controle de sua vida por meio do empoderamento individual. Ao fazer uma reflexão sobre sua condição (tomada de consciência) e possuir os elementos necessários por meio da ação-reflexão-ação, poderá realizar uma transitividade da consciência ingênua para a crítica.

A partir das considerações anteriores, percebe-se o quanto é importante que os profissionais de saúde a tomem conhecimento da existência dessa clientela e desenvolvam programas de atenção e apoio às essas mulheres. É preciso, então, reorientar a prática profissional, deixando de reproduzir a ideologia dominante nas atividades diárias.

Uma das maneiras de possibilitar a libertação dessas mulheres cuidadoras é desvestir o nosso discurso de ideologias dominantes que reforçam a opressão e dificultam o processo de empoderamento por meio da alienação dos cuidadores, alimentando a "cultura do silêncio" reforçando o papel da boa mãe, excluindo o restante da família do processo de cuidar da criança em um processo de responsabilização e culpabilização da "mãemulher-cuidadora".

Nesse sentido, as matrizes teóricas do empoderamento para o cuidado de CRIANES perpassam pela realização de um cuidado participativo centrado na família, incluindo a criança na comunidade com a garantia do pleno gozo dos seus direitos previstos em Lei. Dessa forma, o cuidado pautado no empoderamento coletivo possibilita a inclusão social e a busca de uma vida com mais qualidade para essas crianças e suas cuidadoras.

Empoderada, a mulher pode exigir seus direitos, exercer sua cidadania de forma plena, garantir um cuidado de qualidade para a criança, tomar decisões compartilhadas com os profissionais que atendem seus filhos e filhas e estar efetivamente incluída no processo de cuidar. E que as práticas de empoderamento individual, centradas na abnegação e dedicação, possam servir como fonte de reflexão e ação no desenvolvimento do processo de empoderamento coletivo.

\section{REFERÊNCIAS}

1 McPherson MG, Arango P, Fox H, Lauver C, McManus M, Newachek PW, et al. A new definition of children with special health care needs. Pediatrics. 1998 July; 102(1):137-41.

2 Cabral IE. Aliança de saberes no cuidado e estimulação da criança-bebê: concepções de estudantes e mães no espaço acadêmico de enfermagem. Rio de Janeiro (RJ): Editora da Escola de Enfermagem Anna Nery; 1999.

3 Cabral IE, Moraes JRMM, Santos FF. O egresso da terapia intensiva neonatal de três instituições públicas e a demanda de cuidados especiais. Esc Anna Nery Rev Enferm. 2003 Ago; 7(2):211-8.

4 Vernier-Neves ET. O empoderamento de cuidadoras de crianças com necessidades especiais de saúde: interfaces com o cuidado de enfermagem [tese]. Rio de Janeiro: Universidade Federal do Rio de Janeiro. Escola de Enfermagem Anna Nery. Programa de Pós-graduação em Enfermagem; 2007.

5 Freire P. Conscientização: teoria e prática da libertação. Rio de Janeiro (RJ): Paz e Terra; 1980.

6 Kar SB, Pascual CA, Chickering KL. Empowerment of women for health promotion: a meta-analysis. Soc Sci Med. 1999 Dec; 49(11):1431-60.

7 Meyer DEE. As mamas como instituintes da maternidade: uma história do passado. Educ Realidade. 2000 Jul-Dez; 25(2):117-34.

8 Duro CLM. Maternidade e cuidado infantil: concepções presentes no contexto de um programa de atenção à saúde da criança - Porto Alegre/ Rio Grande do Sul. 2002. [mestrado]. Porto Alegre: Universidade Federal do Rio Grande do Sul. Programa de Pós-Graduação em Enfermagem, 2002.

9 Campbell C, MacPhail C. Peer education, gender and development of critical consciousness: participatory HIV prevention by South African youth. Soc Sci Med. 2002 Jul; 55(2):331-45.

10 Cabral IE. Uma abordagem criativo-sensível de pesquisar a família. In: Althoff CR, Elsen I, Nitschke RG, organizadores. Pesquisando a família: olhares contemporâneos. Florianópolis (SC): Papa-livro; 2004. p.127-39.

11 Bergold LB, Alvim, NAT, Cabral, IE. O lugar da música no espaço do cuidado terapêutico: sensibilizando enfermeiros com a dinâmica musical. Texto Contexto Enferm. 2006 Abr-Jun; 15(2):262-9.

12 Orlandi EP. Análise de Discurso: princípios e procedimentos. $6^{\text {a }}$ ed. São Paulo (SP): Pontes; 2005.

13 Eddy LL, Walker AJ. The impact of children with chronic health problems on marriage. J Fam Nurs. 1999 Aug; 5(1):10-32.

14 Mentro AM. Health care policy for medically fragile children. J Pediatr Nurs. 2003 Aug; 18(4):225-32. 
$15 \mathrm{O}^{\prime}$ Brien ME. Living in a house of cards: family experiences with long-term childhood technology dependence. J Pediatr Nurs. 2001 Feb; 16(1):13-22.

16 Gibson $\mathrm{CH}$. The process of empowerment in mothers of chronically ill children. J Adv Nurs. 1995 June; 21(6):1201-10.

17 Breslau ES. The continuum: somatic distress to medicalization in women with breast cancer: theoretical and empirical assessment. In: Segal MT, Demos V, organizadores. Gender perspectives on health and medicine: key themes. Advances in gender research. v. 7. Toronto (Ontario): Elsevier; 2003.
18 Raina $\mathrm{P}, \mathrm{O}^{\prime}$ Donnell $\mathrm{M}$, Schwellnus H, Rosenbaum $\mathrm{P}$, King G, Brehaut J, et al. Caregiving process and caregiving burden: conceptual models to guide research and practice. BMC Pediatrics. [periódico da Internet]. 2004 Jan [acesso em 2008 Jul 08]; 4(1): [13 p.] Disponível em: http:/ / www.biomedcentral. com/1471-2431/4/1

19 Kirmayer LJ, Groleau D. Affective disorders in cultural context. Psychiatry. 2001 Sep; 24 (3):465-78.

20 Carnevale AF, Alexander E, Davis M, Rennick J, Troini, R. Daily living with distress an enrichment: the moral experience of families with ventilator-assisted children at home. Pediatrics. 2006 Jan; 117(1):48-60. 